\title{
Revelando imagens da Congada: fotografia, memória e pesquisa etnográfica
}

Tese de doutorado em Antropologia Social defendida em 2010 na Faculdade de Filosofia, Letras e Ciências Humanas - USP Orientadora: Profa. Dra. Sylvia Caiuby Novaes

Lilian Sagio Cezar

E-mail: Isagio@hotmail.com

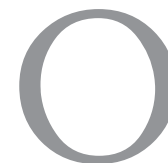

presente texto tem como objetivo discutir algumas das especificidades da pesquisa desenvolvida a partir da utilização e realização de imagens, em especial as fotográficas, em Antropologia. A partir de pesquisa de campo junto aos congadeiros e moçambiqueiros do município mineiro de São Sebastião do Paraíso, e da proposta de realizar e devolver fotografias de sua tradicional Festa de Congada, foram construídos feixes de relações que permitiram a realização $d a$ pesquisa focando as especificidades desta festa, visando o acesso à algumas das profundas camadas de significados das ações, representações e memórias de seus dançadores mais dedicados, elementos estes que geralmente permanecem restritos aos fechados círculos dos realizadores em forma de fundamento ou segredo.

No município mineiro de São Sebas- tião do Paraíso a Festa de Congada acontece há pelo menos 180 anos (CALAFIORI, 1996: 484). A festa é organizada por grupos denominados "ternos de Congo" ou "ternos de Moçambique", compostos pelos descendentes dos antigos escravos, ainda hoje a população economicamente menos abastada do município. Cada um dos 15 ternos da cidade está organizado e mantido por um capitão, um presidente e um benzedor, sendo que as atribuições desses variam conforme a especificidade e a história de cada grupo.

Esta Festa de Congada acontece em louvor aos seis Santos da Congada, também chamados de Santos do Natal: Nossa Senhora do Rosário, São Benedito, Santa Efigênia, São Domingos, Santa Catarina e São Jerônimo. Hierarquicamente constituída pela Rainha Perpétua, Rei Congo, Rainha Conga, Vice-Rei Congo e duas Princesas, a realeza 
da Congada cumpre a missão de proteger, guardar e cultuar os seis santos da festa.

A Congada em São Sebastião do Paraíso se constitui enquanto festa afro-descendente que rememora ritualística e performaticamente, por meio da homenagem a uma corte negra, uma África ancestral contraposta à experiência do trauma da escravidão. Ao se afirmar enquanto festa religiosa católica, essa Congada estabelece para si um espaço físico e temporal legítimo para a sua realização, calcado na própria história da Igreja Católica, em especial, a das irmandades de Nossa Senhora do Rosário. Por conta de seu caráter secular inferiu-se a essa festa o tradicional num duplo sentido, o da história da Igreja e de suas irmandades religiosas e o de memórias ancestrais africanas, o que por si só constitui fonte de polissemia.

Hoje a festa é burocrática e administrativamente coordenada pela Comissão Organizadora da Festa da Congada cujas ações estão subordinadas à Prefeitura Municipal que realiza o repasse de verbas para o custeio dos desfiles dos ternos, a instalação de infraestrutura de arquibancadas, holofotes, palanques, equipamento de amplificação de som que são anualmente montados ao longo da extensão da praça da Matriz de São Sebastião para receber os desfiles que acontecem nas noites da festa. É também ao lado da Matriz que as Bandeiras estampadas com as imagens dos seis santos da festa são "levantadas" nos mastros; concomitantemente as imagens dos seis santos da Congada em seus respectivos andores ficam expostas, os membros da realeza da festa zelam e recebem os reis e rainhas de promessa durante as tardes de 26 a 30 de dezembro de cada ano.

Para esse trabalho, algumas fotografias que realizei entre 2002 e 2005 em diferentes momentos da Congada foram selecionadas e devolvidas aos membros do grupo de congadeiros e moçambiqueiros que se tornaram meus principais interlocutores nesta pesquisa. Estes momentos constituíram processos ricos onde as fotografias que trouxe motivaram comentários dos mais diversos: identificação e nome de pessoas que eu não conhecia e que fazem parte das redes de relações pessoais articuladas pela festa, preocupações a respeito dos santos, da hierarquia, ordem e necessidade da representação de suas imagens, preocupações sobre o devido cumprimento de promessas feitas aos santos da Congada pelos reis e rainhas de promessa, comentário sobre pessoas que tinham falecido etc.

Por sua relevância para a pesquisa filmei o processo de devolução de fotografias à Rainha da Congada, a rainha Geni (Genuita Pereira de Paula) em novembro de 2006. Neste processo eu e a rainha Geni estávamos diante de representações imagéticas de situações que vivenciamos juntas: ela na condição de Rainha Conga, autoridade da Congada, eu na condição de pesquisadora-fotógrafa que buscava conhecer a festa por meio da construção de fotografias. As imagens dos eventos 
representados reavivam a memória dos sujeitos, desencadeiam lembranças, que despontam em diferentes leituras possíveis a partir de imagens. As preocupações estéticas e acadêmicas que tentei materializar naquelas fotografias subsumiam diante daquele encontro de olhares que se debruçavam sobre as mesmas no sentido de poder lhes conferir significados, arranjos, narrativas distintas das minhas. As expectativas, consensos e contradições entre os interesses da antropóloga-fotógrafa e dos seus interlocutores puderam ser explicitados nas falas, comentários e atitudes ao longo da entrevista, sendo que eles também foram filmados e posteriormente editados. [FIG. 1]

As fotografias que apresentei à rainha Geni permitiram que recordações aflorassem sobre festas passadas e potencializaram falas e comentários, alguns de foro muito íntimo, sobre as pessoas ali representadas e experiências vividas. Momentos diferentes da festa e grande número de atores eram representados ao olhar de minha interlocutora e às lentes da câmera de vídeo que eu empunhava.

Num destes lances, a fotografia que representava a imagem de Nossa Senhora do Rosário em seu andor enfeitado apareceu de ponta-cabeça dentre as fotos que compunham

\section{Figura 1}

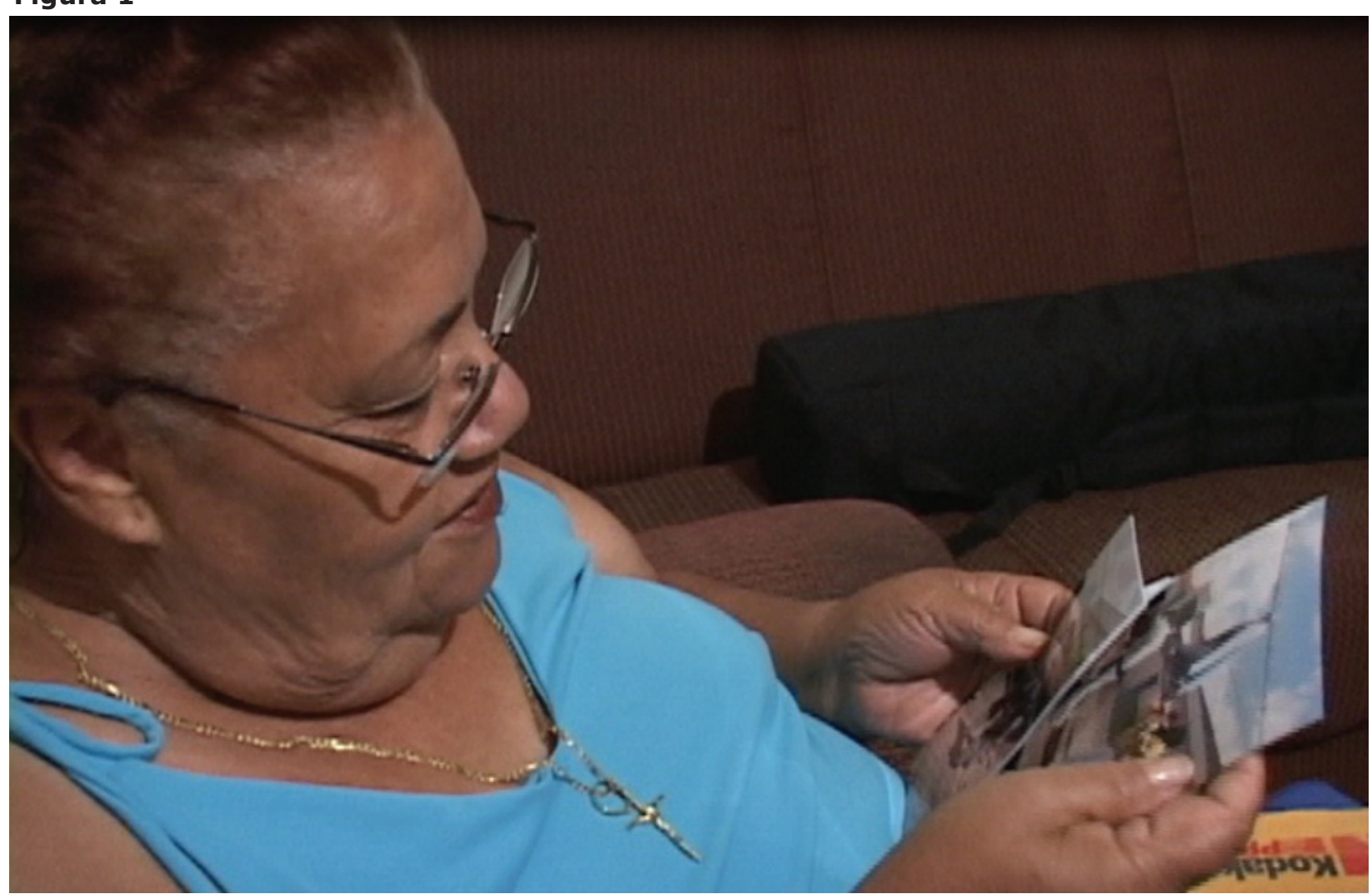

Rainha Geni durante a devolução de fotografias 
aquela sequência. Imediatamente, dona Geni arrumou a foto da santa a colocando de pé dizendo: "Ô coitadinha! Não pode ficar de ponta cabeça". Em seguida a rainha Geni notou o fato de eu ter fotografado separadamente todos os andores já sendo conduzidos nos ombros de quatro dançantes pela procissão e não ter realizado semelhante imagem do andor que conduziu Santa Catarina. A ausência da representação de um dos santos dentre a sequência de seis andores impediu que ela os colocasse na ordem de culto, homenagem e dias da festa atribuídos a cada um dos santos. Essa foi considerada uma imensa falta de atenção e respeito para com cada um dos santos, o que gerou uma chamada de atenção dela para comigo, sem que, no entanto, o motivo para essa bronca tenha sido revelado. Ela só fez aquele ar de "você sabe por que". [FIG. 2]

Ao final dessa devolução de fotografias, já com a família toda reunida ao lado da rainha Geni para ver aquelas imagens, Priscila, neta da rainha Geni, coloca o CD do terno

\section{Figura 2}

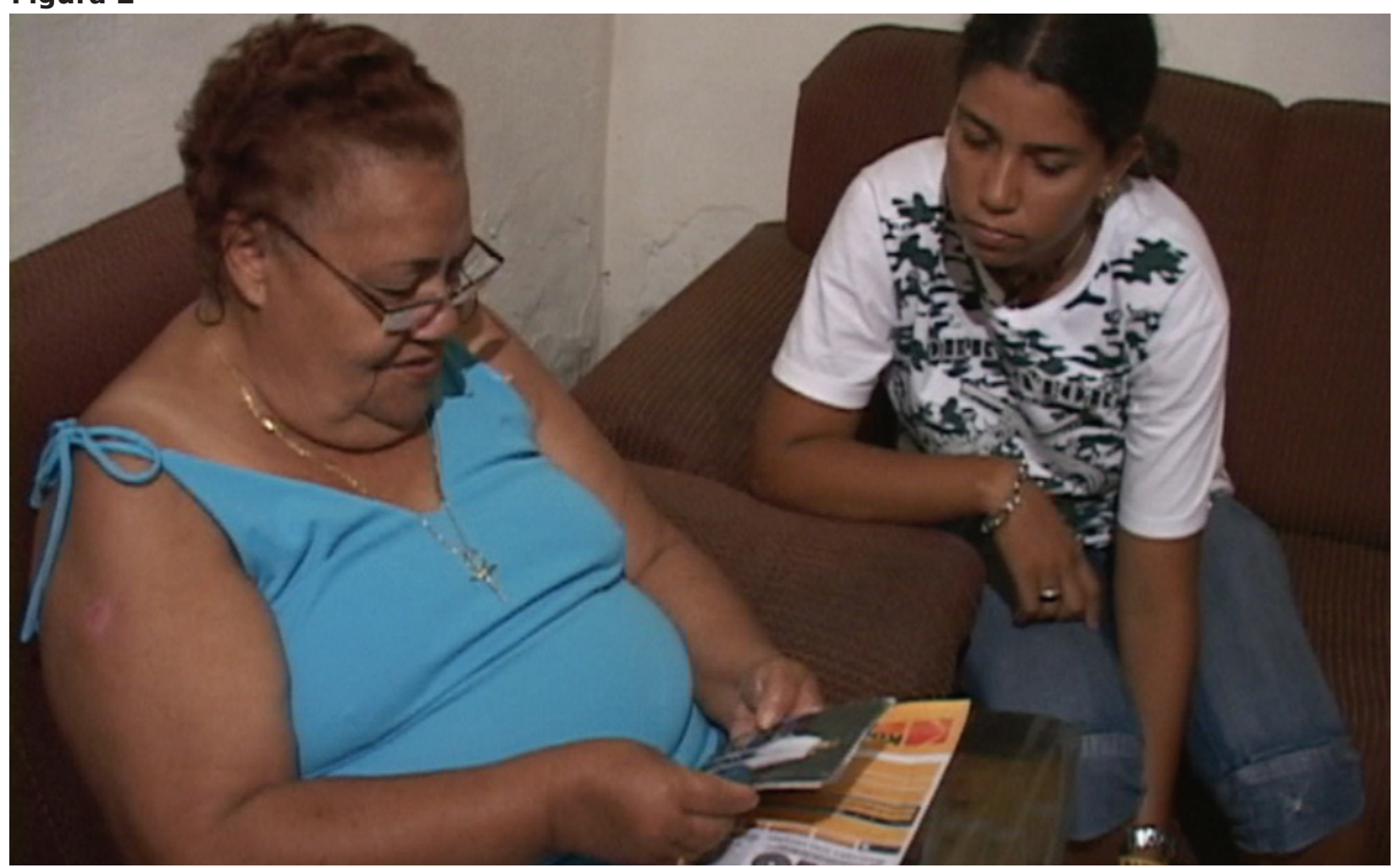

Rainha Geni ao lado de sua neta Priscila. Ao ver que a fotografia da Nossa Senhora do Rosário estava de ponta cabeça, a rainha diz: "Oh, cotadinha! Tá de cabeça para baixo", desvirando imediatamente a foto. Na Congada as imagens dos santos da festa constituem o meio de caracterizar o divino de modo multidimensional. Nesse sentido, as Bandeiras, as imagens nos andores, e mesmo as fotografias que representam estas imagens são os santos, e cada santo desperta especial respeito e devoção nos dançadores. 
de Congo Xambá para ser reproduzido no aparelho de som. Naquele momento pensei a partir das preocupações de quem faz um filme: o som das músicas reproduzidas certamente impediria que eu realizasse a seleção, corte e edição dos conteúdos daquelas falas. Isso porque, por meio da edição, um trecho falado no início da entrevista pode ser unido a outro do final e vice-versa; mas para isso acontecer deverá haver uma homogeneidade nas imagens e sons em relação ao contexto (tempo e espaço) representado. A música quebra essa homogeneidade ao incluir o seu ritmo e melodia àquela sequência-temporal imagética, restringindo assim a operação de corte e edição. [FIG. 3]

Meus interlocutores trouxeram para aquele momento um novo elemento que, como a fotografia, também é um produto do acesso e utilização da tecnologia enquanto registro e suporte de memória, não mais das imagens, mas das músicas compostas e tocadas exclusivamente para a Festa da Congada. Rainha Geni escolheu uma música em especial e me disse: "escuta, escuta essa música”, e Rosângela completou "ela fala de meu pai”"

A música em questão chama-se Majesta-

\section{Figura 3}

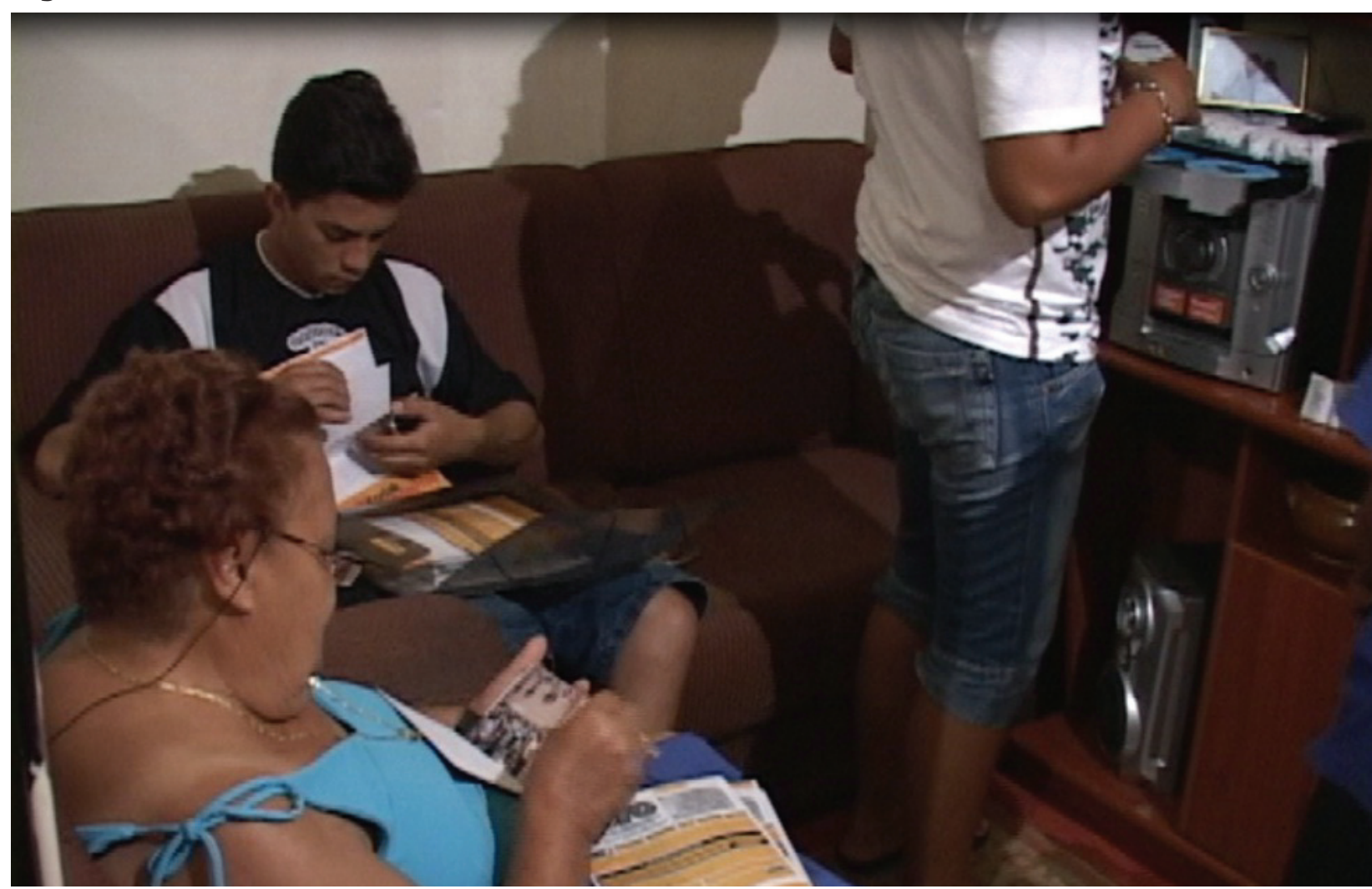

Rainha Geni e seus netos Priscila e Alex se reúnem ao redor das fotografias e das músicas da Festa da Congada

RESGATE - Vol. XVIII, No. 19 - jan.jjul. 2010 - CEZAR, Lilian Sagio - p.171-179 
de do Congado, [1] foi composta para homenagear a já falecida, antiga Rainha Conga Geralda Batista, e faz isso descrevendo sua chegada na outra dimensão, onde foi recebida e se juntou aos outros congadeiros e moçambiqueiros já falecidos, dentre eles o marido e o sogro de rainha Geni, ambos falecidos Reis Congo da Congada. Essa música encerra uma lista de nomes de pessoas que foram importantes para esta festa que são reverenciadas no presente. Nomes lembrados dentro dos valores e da forma privilegiada de discurso da Congada que é o canto e a música. Nomes que, segundo suas famílias, não podem ser esquecidos. Nomes que são reconhecidos devido à importância da cada uma dessas pessoas para a realização da festa. Nomes que quando lembrados dão acesso à memória dos ganhos de experiências pessoais vividas com cada uma dessas pessoas e, concomitantemente, ao sentimento de perda pela falta daquela pessoa no convívio cotidiano das festas. Foi essa emoção despertada pela música que fez rolar lágrimas na rainha Geni.

As imagens filmadas que representam esse processo de pesquisa captaram o fluxo da narrativa, da sensibilidade, afetividade e memória, servindo como meio de acesso às interpretações criadas e transmitidas discursivamente pela rainha Geni, protagonista da construção de um conhecimento a partir dessas fotografias, enquanto artefatos que selecionaram eventos para fixá-los e, assim, materializaram o olhar da pesquisado- ra-fotógrafa sobre a festa. Nessa simples atitude a representação imagética que fiz da Congada foi lida e apropriada a partir das expectativas e sentidos que se articulam aos padrões estruturais significativos do mundo que é criado anualmente pela própria festa. Isto permitiu que o lugar preponderante de escolha e seleção de imagens, ocupado pela pesquisadora-fotógrafa, fosse subvertido pela narrativa da rainha Geni, que estabeleceu outros vínculos entre as imagens, lançando mão para isso da afetividade de quem se vê e vê a sua festa representadas nas fotografias. Concomitantemente, o procedimento de apresentar a câmera de vídeo por meio da devolução de fotografias parece ter trazido uma certa familiaridade a esse instrumento o que lhe conferiu melhor receptividade em momentos distintos daqueles da festa em que as atitudes filmáveis são, em princípio, às geralmente veiculadas pela mídia, em que sobressaem a exaltação desta Festa de Congada enquanto espetáculo.

A continuidade do processo de pesquisa por meio da construção do filme seguindo as orientações do cinema de observação (HENLEY, 2004: 164) fizeram-me roteirizar, editar e exibir um experimento fílmico que denominei "Fotos para Geni" que, como o próprio nome diz, apresenta a Festa da Congada, alguns de seus conflitos e ações rituais tendo a devolução das fotografias à rainha Geni como fio condutor narrativo. A forma como empreguei a fotografia no de- 
senvolvimento deste processo de pesquisa a coloca num meio lugar entre a imagem fixa e a imagem em movimento, seja por meio da realização do experimento fílmico calcado na devolução de fotografias para minha interlocutora, seja pelo ir e vir perambulando atrás das imagens fotográficas encontradas nos quatro cantos da cidade, ou ainda nas casas dos meus amigos congadeiros e moçambiqueiros. $\mathrm{O}$ certo é que essas imagens inicialmente fixas foram processualmente desfiadas nas conversas, nas narrativas, na leitura de suas entrelinhas. Assim a fala potencializou a fotografia. A fotografia potencializou o vídeo. O vídeo potencializou a fotografia. A fala potencializou o vídeo. Assim me vali das trocas advindas desses intrincados processos de espelhamento e refração de imagens.

Para a análise dos dados obtidos por meio da pesquisa de campo envolvendo imagens articulei a sincrônica descrição etnográfica da festa ao cotejamento de recortes conceituais diacrônicos em que documentos estudados pela historiografia recente ofereceram elementos importantes à compreensão da Congada em sua especificidade de imbricar heranças africanas de religiosidade às práticas católicas.

Ao focar a investigação nas imagens da Congada pude rastrear os nexos e sentidos correlacionados à dinâmica conceitual da festa e ao processo social de construção de sentido que tem como base as experiências cotidianas e as relações entre as pessoas e os santos, deuses, entidades e energias que constituem o mundo envolvente, mundo esse do qual a Congada é uma das festas em que o visível e o invisível se manifestam.

A intensidade das demonstrações de afetividade dos dançadores para com os santos, Bandeiras e imagens da Festa da Congada foram metaforizadas nas fotografias e vídeos que fiz durante o percurso da pesquisa de campo. Estas reapresentam as imagens que dão forma às agências da Festa da Congada enquanto são esteticamente decoradas, saudadas, performaticamente conduzidas, passeadas, referenciadas, tocadas, beijadas em relações sensoriais onde o que está em jogo nestas performances é a imanência da presença física das divindades.

As divindades que constituem a Festa da Congada, Nossa Senhora do Rosário, São Benedito, Santa Efigênia, São Domingos, Santa Catarina e São Jerônimo possuem caráter múltiplo e são muitas vezes assumidas como ancestrais comuns aos dançadores. É nesse sentido que santos e ancestrais são aproximados em suas características comuns conformando veículos a partir dos quais afetos, sentimentos e expectativas transitam entre mundos distintos.

A estética da Congada expressa os 
conceitos referentes aos santos e ancestrais agenciados por meio dos rituais e performances constituintes da festa. Predicados como humildade, pobreza e caridade fundamentam a idéia do que foi a vida tanto dos santos como dos escravos ancestrais, conceitos que hoje modulam as atitudes, escolhas e ações dos dançadores mais dedicados. Exemplo disso está na conformação deliberada de pequenos ternos com restrito número de pessoas, na recusa de dançadores em usar sapatos para participar dos cortejos de alguns ternos tendo os pés descalços durante os desfiles, na utilização de tipos de tecidos tidos como menos nobres como o chitão [2] e o cetim brilhante estampados em cores fortes, abertas e vibrantes como material preferencial para a confecção das vestimentas e adornos que decoram os corpos dos dançadores durante sua festa.

A Congada atualiza o contato entre mundos distintos oferecendo aos humanos a possibilidade de acesso às potências presentes numa dimensão que lhes é imediata e sensivelmente interditada. Humanos se valem dos rituais, mitos, imagens, adereços, instrumentos musicais, canções enquanto veículos deste contato onde conteúdos específicos são comunicados em mensagens distintas que reiteradamente informam a intenção e possibilidade de acesso e culto a determinados santos, entidades e ancestrais por meio da festa.
Em decorrência disso, os símbolos presentes na Congada são atribuídos por seus dançadores a uma estética específica que traz para o mundo visível cores, valores e atributos correspondentes a tais potências. As performances que constituem a festa recontam a história que congadeiros e moçambiqueiros contam de si mesmos, suas origens e concepções de mundo, para si mesmos. O objetivo desse contar e recontar histórias encerra um processo de expressão simbólica em que linguagens distintas narram e constroem autoimagens.

Essa pesquisa é assim, resultado da investigação de processos de percepção atribuídos ao olhar que se reportam ao mundo visível, mas também ao mundo invisível, cuja apreensão e compreensão abarcam códigos, modulação e educação dos sentidos de ordem diversa e específica. Os atores conhecedores desses saberes reportam tais práticas, aptidões, habilidades e hábitos visuais à herança escrava africana no Brasil. O elo de descendência consangüínea direta assim como a aprendizagem a partir de mestres que, por sua vez, se reportam a seus mestres africanos, é utilizado na explicação, atribuição e valorização dos saberes específicos da Congada.

A utilização da imagem me ajudou a descrever e, concomitantemente, materializar uma trajetória de pesquisa. Isso 
fez com que a imagem assumisse o papel de um tipo de suporte de memória, que é seletivo, carregado de intenções e preocupações teóricas específicas que nesse caso diz respeito ao próprio desenvolvimento desta pesquisa. Esse foi o caminho para acessar os significados, padrões e preocupações que meus interlocutores liam nessas mesmas imagens a partir de seus repertórios e expressos em seus próprios termos.

\section{REFERÊNCIAS BIBLIOGRÁFICAS}

CALAFIORI. Luis Ferreira. São Sebastião do Paraíso: Histórias e Tradições. São Sebastião do Paraíso (MG): Prefeitura Municipal, 1996. HENLEY, Paul. "Trabalhando com o filme: cinema de observação como etnografia prática". Cadernos de Antropologia e imagem. Rio de Janeiro: UERJ, NAI, 2004, N. 18 (1), pp. 163-188.

\section{Notas}

1 - Música composta por José Salvador Eustáquio, o Gorvalho, capitão do terno de Congo Xambá com seus parceiros Quarenta e Corrente.

2 - Tecido à base de algodão tingido com estampas de flores grandes, pintadas com cores fortes, coloridas e vibrantes. Enquanto a chita traz estampas de flores pequeninas, o chitão apresenta flores grandes. Este tecido remonta padrões estéticos até hoje usados na África e se vale de cores fortes para a estamparia usada na confecção de roupas. 